\title{
Immunohistochemical expression of CDX2 gene in colorectal carcinoma
}

\begin{tabular}{|c|c|c|}
\hline Tavga Hushair Dizeyi* & Rafal Abdulrazaq Al-Rawi** & Ava Taher I smael** \\
\hline
\end{tabular}

Background and objective: Colorectal cancer is a multi-factorial disease process, with etiology encompassing genetic factors, environmental exposures, and inflammatory conditions of the digestive tract. This study aimed to investigate the immunohistochemical expression of CDX2 as well as clinical and histopathological parameters of patients with colorectal cancer in Erbil, Kurdistan.

Methods: A retrospective study including about 100 colorectal cancer cases in Erbil city, Kurdistan was conducted from January 2015 to January 2017. Tumor type, site, size, histological grade, lymph node status, and pathological stage with CDX2 expression were investigated.

Results: CDX2 was expressed in 86 out of $100(86 \%)$ patients. It was more expressed (focal or diffuse staining) in nonmucinous carcinoma more than signet ring and mucinous carcinoma. Loss of CDX2 expression in colorectal cancer is associated with a high tumor grade and stage. Significant associations between CDX2 expression with both tumor type and tumor grade were observed. Although CDX2 expression was found to be reduced in proximal location (right colon) and higher stage, however, no significant associations between CDX2 expressions in colorectal cancer were detected with tumor site, nodal status, and tumor stage.

Conclusion: Reduced and loss CDX2 expression in colorectal cancer associated with high tumor grades as well as with the mucinous and signet ring cell carcinomas may reflect aggressive tumor behavior probably because of the CDX2 tumor-inhibitory properties. However, the full extent of CDX2's antitumor effects has yet to be elucidated.

Keywords: Colorectal cancer; CDX2 expression; Immunohistochemistry.

\section{Introduction}

Colorectal cancer, the most common type of gastrointestinal cancer, is the third most commonly diagnosed cancer in both men and women. ${ }^{1}$ In Iraq, It is the $7^{\text {th }}$ most frequent cancer, while in Kurdistan, it forms the $4^{\text {th }}$ most prevalent cancer. ${ }^{2}$ This cancer affects nearly 1 million patients worldwide every year, with an average survival rate of less than $50 \%$ which forms the third major cause of cancer-related deaths. ${ }^{3}$ Risk factors for developing colorectal cancer include prolonged inflammation in the bowel, low physical activity, obesity, high alcohol consumption as well as high intake of red meat. ${ }^{4}$ Development of colorectal cancer is a multistep process, wherein specific genes are more to be mutated or over expressed than others. ${ }^{5}$ CDX2 gene maps to chromosome 13q12.3 which has three exons and encodes a 313 amino acids protein. ${ }^{6}$ It is expressed during endoderm development and in adult intestine. ${ }^{7}$ The role of CDX2 started to be established when it was observed in the undifferentiated intestinal cell line (IEC-6) which arrests proliferation and initializes an epithelial polarity program. ${ }^{8}$ Cell proliferation and differentiation were thus tightly controlled in the normal intestinal epithelium. Various genes and transcription factors may be involved in this process;

* Department of Microbiology, College of Health Sciences, Hawler Medical University, Erbil, I raq

** Department of Clinical Analysis, College of Pharmacy, Hawler Medical University, Erbil, I raq. 
one of these is CDX2 which is a nuclear transcription factor that is essential for regulating genes related to epithelial functions, ${ }^{9}$ and controlling the balance between differentiation and proliferation of IECs. ${ }^{8}$ The caudal-related CDX2 gene encodes an intestinal-specific transcription factor that has been suggested to be crucial for the development of the intestinal epithelium. ${ }^{10} \mathrm{CDX} 2$ was required for columnar morphogenesis and cell differentiation in the normal intestinal epithelium. ${ }^{11}$ CDX2 had also been suggested to be a tumor suppressor in the colon. ${ }^{12}$ Furthermore, loss of CDX2 expression promotes tumor progression in genetically, and chemically induced colorectal cancer. $^{13}$ This study aimed to investigate the immunohistochemical expression of CDX2 as well as clinical and histopathological parameters of patients with colorectal cancer in Erbil, Kurdistan.

\section{Methods}

One hundred formalin-fixed, paraffinembedded specimens of colorectal cancer were randomly selected from histopathology departments of the Rizgary Teaching Hospital and private histopathology labs during the period, between January 2015 and January 2017. The study was approved by the Kurdistan Board of Medical Specialties (KBMS). The single exclusion criterion was a CDX2 expression in secondary metastatic colorectal adenocarcinoma. Demographic data (age at diagnosis and sex) and the topography of the tumor (location, histological type of tumor, nodal status) were obtained from the patient's request forms. All blocks were examined, and the best-represented tumor blocks (no necrosis, no much mesenchymal tissue) were selected. New sections were made and stained with Hematoxylin and Eosin H\&E for reevaluation. Tumors were divided according to the anatomical location into right, left, and rectal. Histological grading was based on reviewing the H\&E stained slides and labeled as the G1 for well-moderately differentiated, G2 for poorly differentiated cases, and histological tumor type as mucinous and nonmucinous. The staging was performed according to the American Joint Committee on Cancer (AJCC) and the Union international center le cancer (UICC), by grouping the various TNM components, as T1-T2 and T3-T4. CDX2 immunoscore measurement was assessed by two investigators; only nuclear staining was considered positive. Cytoplasmic positivity was infrequently encountered and was considered as an artifact. Tumors were graded according to the percentage of positive cells and were scored quantitatively according to the 3 -tiered system as following. ${ }^{14} 1=$ negative $(<5 \%), 2=$ focal positive $(<50 \%), 3=$ diffuse positive ( $\geq 50 \%)$. In general, cases showing 2 and three staining patterns also had strong, intense staining, so the intensity was not used in the determination of the final reactivity score. Normal colonic mucosal tissue was used as a CDX2positive control. For negative controls, the primary antibody was omitted in each run. ${ }^{15} \mathrm{~A}$ Mouse Monoclonal Anti-Human CDX2 Ready-to-Use (Dako Autostainer/ Autostainer Plus) was used. Labeled polymer and enhanced polymer system (Dako EnVision ${ }^{\mathrm{TM}}$ Flex) method according to Dako recommendation was used to stain tissue by the Anti-CDX2 antibody.

\section{Statistical analysis}

All patients' data were analyzed using computerized statistical software, the statistical package for the social sciences (version 20). Descriptive statistics were presented as mean \pm standard deviation and percentages. Multiple contingency tables conducted and appropriate statistical tests were performed. Chisquare was used for categorical variables. Fisher's exact test was performed when the expected count of more than $20 \%$ of the cells of the table was less than 5 . In all statistical analysis, the level of significance ( $P$ value) was set at $\leq 0.05$. 


\section{Results}

A total of 100 patients with colorectal cancer (median age: 43 years, range: 19 - 85 years) were included in this study. The male to female ratio was $0.75: 1$ (43 males and 57 females). Clinicopathological variables are presented in Table 1 . Sixty-eight patients had left colon and sigmoid cancer, whereas 32 patients had right colon cancer. Only 13 patients were diagnosed with mucinous adenocarcinoma, while the remaining 87 had non-mucinous adenocarcinoma. A total of 47 cases were at stage T1, T2 colorectal cancer while 53 patients showed stage T3, T4 colorectal cancer, and 53 patients had positive lymph nodes at the time of diagnosis.

Table 1: Descriptive data of cases.

\begin{tabular}{|c|c|c|c|}
\hline Variables & Categories & No. & $\%$ \\
\hline \multirow[t]{2}{*}{ Age groups } & $<50$ years & 35 & 35 \\
\hline & $\geq 50$ years & 65 & 65 \\
\hline \multirow[t]{2}{*}{ Gender } & Male & 43 & 43 \\
\hline & Female & 57 & 57 \\
\hline \multirow[t]{2}{*}{ Site of cancer } & Right colon & 32 & 32 \\
\hline & Left colon and sigmoid & 68 & 68 \\
\hline \multirow[t]{2}{*}{ Tumor type } & Non-mucinous & 87 & 87 \\
\hline & Mucinous \& signet ring cell carcinomas & 13 & 13 \\
\hline \multirow[t]{2}{*}{ Tumor grade } & Well - moderate & 89 & 89 \\
\hline & Poor & 11 & 11 \\
\hline \multirow[t]{2}{*}{ Nodal status } & Negative & 47 & 47 \\
\hline & Positive & 53 & 53 \\
\hline \multirow[t]{2}{*}{ Stage of cancer } & $\mathrm{T} 1, \mathrm{~T} 2$ & 47 & 47 \\
\hline & $\mathrm{T} 3, \mathrm{~T} 4$ & 53 & 53 \\
\hline Total & & 100 & 100 \\
\hline
\end{tabular}


There was a significant association association between tumor grade (well$(P=0.04)$ between tumor type with a CDX2 expression level. Eighty-nine cases were well-moderate differentiated, and 11 were poorly differentiated tumors. A significant moderate versus poor) $(P=0.006)$ was found. No significant association between nodal status with an expression of CDX2 was demonstrated (Table 2).

Table 2: Association of CDX2 expression with patient's age, gender and tumor measures.

\begin{tabular}{|c|c|c|c|c|c|c|c|c|c|}
\hline \multicolumn{2}{|c|}{ Characteristics } & \multicolumn{6}{|c|}{ Number (No.) and \% of CDX2 expression } & \multirow{3}{*}{ Total } & \multirow{3}{*}{$P$ value } \\
\hline & & \multicolumn{2}{|c|}{ Negative } & \multicolumn{2}{|c|}{ Focal } & \multicolumn{2}{|c|}{ Diffuse } & & \\
\hline & & No. & $\%$ & No. & $\%$ & No. & $\%$ & & \\
\hline \multirow[t]{2}{*}{ Age } & More than 50 years & 10 & $(15.4)$ & 28 & $(43.1)$ & 27 & $(41.5)$ & 65 & \\
\hline & Less than 50 years & 4 & $(11.4)$ & 15 & $(42.9)$ & 16 & $(45.7)$ & 35 & 0.84 \\
\hline \multirow[t]{2}{*}{ Gender } & Male & 7 & $(15.9)$ & 19 & $(43.2)$ & 18 & $(40.9)$ & 44 & \\
\hline & Female & 7 & $(12.5)$ & 24 & $(42.9)$ & 25 & $(44.6)$ & 56 & 0.86 \\
\hline \multirow[t]{2}{*}{ Tumor type } & Non-mucinous & 10 & $(11.5)$ & 36 & $(41.4)$ & 41 & $(47.1)$ & 87 & \\
\hline & Mucinous & 4 & $(30.8)$ & 7 & $(53.8)$ & 2 & $(15.4)$ & 13 & 0.04 \\
\hline \multirow[t]{2}{*}{ Tumor grade } & Well- moderate & 9 & $(10.1)$ & 40 & $(44.9)$ & 40 & $(44.9)$ & 89 & \\
\hline & Poor & 5 & $(45.4)$ & 3 & (27.3) & 3 & (27.3) & 11 & 0.006 \\
\hline \multirow[t]{2}{*}{ Tumor stage } & Stage T1, T2 & 4 & (8.5) & 19 & $(40.4)$ & 24 & $(51.1)$ & 47 & \\
\hline & Stage T3, T4 & 10 & ( 8.9) & 24 & $(45.3)$ & 19 & $(35.8)$ & 53 & 0.18 \\
\hline \multirow[t]{2}{*}{ Nodal status } & Negative & 4 & (8.5) & 20 & $(42.6)$ & 23 & $(48.9)$ & 47 & \\
\hline & Positive & 10 & $(18.9)$ & 23 & $(43.3)$ & 20 & (37.7) & 53 & 0.26 \\
\hline \multirow[t]{2}{*}{ Tumor site } & Right colon & 6 & $(18.8)$ & 13 & $(40.6)$ & 13 & $(40.6)$ & 32 & \multirow{2}{*}{0.64} \\
\hline & Left colon & 8 & (11.8) & 30 & (44.1) & 30 & $(44.1)$ & 68 & \\
\hline
\end{tabular}


Although CDX2 expression was found to be reduced in proximal location (right colon), there was no significant relation between negative, focal or diffuse CDX2 expression with tumor sites. Expressions of CDX2 determined by nuclear immunoreactivity are shown in Figure 1.

\section{Discussion}

In this study, CDX2 was expressed in $86(86 \%)$ cases of colorectal adenocarcinomas. This is similar to what has been seen by Kaimaktchiev et al. study $(85.7 \%) .{ }^{16}$ Nuclear staining for CDX2 in $10(100 \%)$ of 10 colonic adenomas and $30(88.2 \%)$ of 34 colorectal adenocarcinomas, ${ }^{17}$ whereas another study found reduced CDX2 expression in $4 \%$ of differentiated adenocarcinomas. ${ }^{18}$ Loss of CDX2 has been detected in $29 \%$ of cases while expressed in $71 \% .^{19}$ Choi et al. in their study on 123 colorectal adenocarcinoma cases, reported a loss of CDX2 immunostaining in $23.6 \%$ while expressed in $76.4 \%$ of cases. ${ }^{20}$ On the other hand, it was stated that CDX2 expression was found in $97 \%$ of colorectal adenocarcinomas. ${ }^{15}$ Loss and reduction of CDX2 expression in colorectal cancer were seen to be associated with high tumor grade and high stage tumors, although the association with tumor stage was not significant. This may be explained by the variability in some cases and to the heterogeneity of CDX2 expression by tumor cells. Previous reports support our
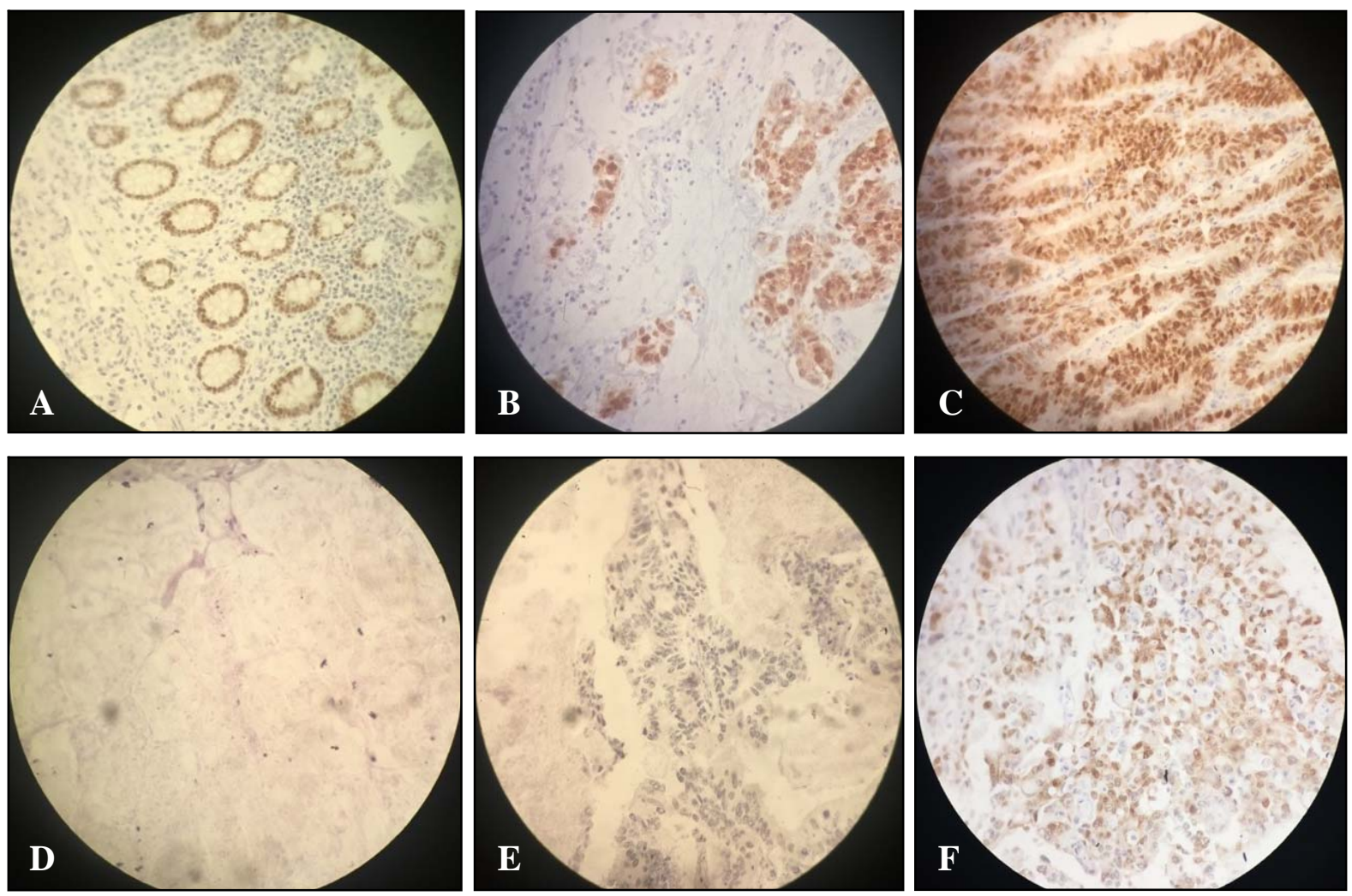

Figure1: Expression of CDX2 determined by immunoreactivity in representative sections of colorectal carcinoma. (A) Positive control of CDX2 expression in nuclei of normal intestinal epithelial cells. (B) Tumor with Focal $(<50 \%)$ expression of nuclear CDX2. (C) Tumor with Diffuse ( $\geq 50 \%)$ expression of nuclear CDX2. (D) Colorectal cancer mucinous adenocarcinoma with negative expression of CDX2. (E) Poorly differentiated colorectal adenocarcinoma with negative expression of CDX2. (F) Colorectal cancer signet ring adenocarcinoma with focal expression of CDX2. (microscopy images magnification: 400x). 
findings considering the loss of CDX2 expression in colorectal cancer associated with high tumor grade or advanced tumor stage. ${ }^{16-18}$ The staining of CDX2 was more (focal or diffuse staining) in nonmucinous carcinoma than signet ring and mucinous carcinomas. This may indicate that there is a loss of CDX2 expression in mucinous and signet ring carcinomas. Some studies reported CDX2 loss association with advanced TNM stage, higher tumor grades, mucinous and signet ring cell histology. ${ }^{19}$ As well, it is in agreement with others who found a negative association between CDX2 expression and tumor stage. ${ }^{16,20-22}$ In contrast, another study showed no association among CDX2 expression with the anatomical location, tumor stage $(T)$, or nodal status ${ }^{14}$ However, Olsen et al. ha ${ }^{d}$ noticed that CDX2 expression was probably correlated to tumor grade, stage, and right-sided tumors. ${ }^{23}$ Another study reported that not all histological subtypes of high-grade tumors exhibit loss of CDX2 expression. ${ }^{24}$ Also, the predilection for female gender and right-sided tumor location has also been observed in other studies. ${ }^{19,25}$ Expression of CDX2 between matched lymph nodes and primary colorectal cancers was also noticed. These results appear to indicate that a further evolution leading to loss of CDX2 after lymph node spread is unlikely. ${ }^{25}$ The full extent of CDX2's antitumor effects has yet to be elucidated. ${ }^{26}$ Moreover, CDX2 plays an important role in the processes of intestinal cell proliferation, differentiation, adhesion, and apoptosis in addition to its contribution as a tumor suppressor gene. ${ }^{27-}$ ${ }^{31}$ Indeed, its expression is often reduced in colorectal cancer and cell differentiation is poor in tumors that lose CDX2 $2^{27-29,32}$ Such concepts indicate that loss of expression of CDX2 may play an important role in the tumorigenesis of colorectal cancers and may categorize patients at high risk. ${ }^{20}$

\section{Conclusion}

In conclusion, reduction and loss of CDX2 expression in colorectal cancer were associated with a high tumor grade, advanced tumor stage, mucinous and signet ring cell carcinomas. This indicates that loss of expression of CDX2 may play an important role in the tumor progression of colorectal cancers. It is recommended that CDX2 should always be used as a part of a broader immunohistochemical panel.

\section{Competing interests}

The authors declare that they have no competing interests.

\section{References}

1. Siegel RL, Miller KD, Fedewa SA, Ahnen DJ, Meester RGS, Barzi A, et al. Colorectal cancer statistics, 2017. CA Cancer J Clin 2017; 67(3):177-93.

2. Othman RT, Abdulljabar R, Saeed A, Kittani SS, Sulaiman HM, Mohammed SA, et al. Cancer incidence rates in the Kurdistan region/Iraq from 2007-2009. Asian Pac J Cancer Prev 2011; 12(5):12614.

3. Boyle $\mathrm{P}$, Leon ME. Epidemiology of colorectal cancer. Br Med Bull 2002; 64:1-25.

4. Jenkins D, Balsitis M, Gallivan S, Dixon MF, Gilmour HM, Shepherd NA, et al. Guidelines for the initial biopsy diagnosis of suspected chronic idiopathic inflammatory bowel disease. The British Society of Gastroenterology Initiative. J Clin Pathol 1997; 50(2):93-105.

5. Barbacid M. ras genes. Annu Rev Biochem 1987; 56:779-827.

6. Trinh KY, Jin T, Drucker DJ. Identification of domains mediating transcriptional activation and cytoplasmic export in the caudal homeobox protein Cdx-3. J Biol Chem 1999; 274(9):6011-9.

7. Silberg DG, Swain GP, Suh ER, Traber PG. $\mathrm{Cdx} 1$ and $\mathrm{cdx} 2$ expression during intestinal development. Gastroenterology 2000; 119(4):961 -71 .

8. Suh E, Traber PG. An intestine-specific homeobox gene regulates proliferation and differentiation. Mol Cell Biol 1996; 16(2):619-25.

9. Boyd M, Hansen M, Jensen TG, Perearnau A, Olsen AK, Bram LL, et al. Genome-wide analysis of CDX2 binding in intestinal epithelial cells (Caco-2). J Biol Chem 2010; 285(33):25115-25.

10. Freund JN, Domon-Dell C, Kedinger M, Duluc I. The $\mathrm{Cdx}-1$ and $\mathrm{Cdx}-2$ homeobox genes in the intestine. Biochem Cell Biol 1998; 76(6):957-69.

11. Guo RJ, Suh ER, Lynch JP. The role of $\mathrm{Cdx}$ proteins in intestinal development and cancer. Cancer Biol Ther 2004; 3(7):593-601.

12. Aoki K, Tamai Y, Horiike S, Oshima M, Taketo MM. Colonic polyposis caused by mTORmediated chromosomal instability in $\mathrm{Apc}+/$ Delta716 Cdx2+/- compound mutant mice. Nat Genet 2003; 35(4):323-30. 
13. Bonhomme C, Duluc I, Martin E, Chawengsaksophak K, Chenard MP, Kedinger $\mathrm{M}$, et al. The $\mathrm{Cdx} 2$ homeobox gene has a tumour suppressor function in the distal colon in addition to a homeotic role during gut development. Gut 2003; 52(10):1465-71.

14. Vang R, Gown AM, Wu LS, Barry TS, Wheeler DT, Yemelyanova A, et al. Immunohistochemical expression of CDX2 in primary ovarian mucinous tumors and metastatic mucinous carcinomas involving the ovary: comparison with CK20 and correlation with coordinate expression of CK7. Mod Pathol 2006; 19(11):1421-8.

15. Bayrak R, Haltas $H$, Yenidunya $S$. The value of CDX2 and cytokeratins 7 and 20 expression in differentiating colorectal adenocarcinomas from extraintestinal gastrointestinal adenocarcinomas: cytokeratin 7-/20+ phenotype is more specific than CDX2 antibody. Diagn Pathol 2012; 7:9.

16. Kaimaktchiev V, Terracciano L, Tornillo L, Spichtin $H$, Stoios $D$, Bundi $M$, et al. The homeobox intestinal differentiation factor CDX2 is selectively expressed in gastrointestinal adenocarcinomas. Mod Pathol 2004; 17(11):1392 $-9$.

17. Bakaris S, Cetinkaya A, Ezberci F, Ekerbicer $\mathrm{H}$. Expression of homeodomain protein CDX2 in colorectal adenoma and adenocarcinoma. Histol Histopathol 2008; 23(9):1043-7.

18. Hinoi T, Tani M, Lucas PC, Caca K, Dunn RL, Macri E, et al. Loss of CDX2 expression and microsatellite instability are prominent features of large cell minimally differentiated carcinomas of the colon. Am J Pathol 2001; 159(6):2239-48.

19. Baba Y, Nosho K, Shima K, Freed E, Irahara N, Philips J, et al. Relationship of CDX2 loss with molecular features and prognosis in colorectal cancer. Clin Cancer Res 2009; 15(14):4665-73.

20. Choi BJ, Kim CJ, Cho YG, Song JH, Kim SY, $\mathrm{Nam} \mathrm{SW}$, et al. Altered expression of CDX2 in colorectal cancers. APMIS 2006; 114(1):50-4.

21. Dalerba P, Sahoo D, Paik S, Guo X, Yothers G, Song N, et al. CDX2 as a Prognostic Biomarker in Stage II and Stage III Colon Cancer. N Engl J Med 2016; 374(3):211-22.

22. Bae JM, Lee TH, Cho NY, Kim TY, Kang GH. Loss of CDX2 expression is associated with poor prognosis in colorectal cancer patients. World J Gastroenterol 2015; 21(5):1457-67.

23. Olsen J, Espersen ML, Jess $P$, Kirkeby $L T$, Troelsen JT. The clinical perspectives of CDX2 expression in colorectal cancer: a qualitative systematic review. Surg Oncol 2014; 23(3):167-76.

24. De Lott LB, Morrison C, Suster S, Cohn DE, Frankel WL. CDX2 is a useful marker of intestinal -type differentiation: a tissue microarray-based study of 629 tumors from various sites. Arch Pathol Lab Med 2005; 129(9):1100-5.

25. Dawson H, Koelzer VH, Lukesch AC, Mallaev M, Inderbitzin D, Lugli A, et al. Loss of Cdx2 Expression in Primary Tumors and Lymph Node
Metastases is Specific for Mismatch Repair-Deficiency in Colorectal Cancer. Front Oncol 2013; 3:265.

26. Gross I, Duluc I, Benameur T, Calon A, Martin E, Brabletz T, et al. The intestine-specific homeobox gene $\mathrm{Cdx} 2$ decreases mobility and antagonizes dissemination of colon cancer cells. Oncogene 2008; 27(1):107-15.

27. Mizoshita T, Inada K, Tsukamoto T, Kodera $\mathrm{Y}$, Yamamura $Y$, Hirai $T$, et al. Expression of $\mathrm{Cdx} 1$ and $\mathrm{Cdx} 2 \mathrm{mRNAs}$ and relevance of this expression to differentiation in human gastrointestinal mucosa--with special emphasis on participation in intestinal metaplasia of the human stomach. Gastric Cancer 2001; 4(4):18591.

28. Bai YQ, Miyake S, Iwai T, Yuasa Y. CDX2, a homeobox transcription factor, upregulates transcription of the p21/WAF1/CIP1 gene. Oncogene 2003; 22(39):7942-9.

29. Suh E, Chen L, Taylor J, Traber PG. A homeodomain protein related to caudal regulates intestine-specific gene transcription. Mol Cell Biol 1994; 14(11):7340-51.

30. Witek ME, Nielson K, Walters R, Hyslop T, Palazzo J, Schulz S, et al. The putative tumor suppressor CDX2 is overexpressed by human colorectal adenocarcinomas. Clin Cancer Res 2005; 11:8549-56.

31. Almeida R, Silva E, Santos-Silva F, Silberg DG, Wang J, De Bolos C, et al. Expression of intestine-specific transcription factors, CDX1 and CDX2, in intestinal metaplasia and gastric carcinomas. J Pathol 2003; 199(1):36-40.

32. Winn B, Tavares R, Fanion J, Noble L, Gao J, Sabo E, et al. Differentiating the undifferentiated: immunohistochemical profile of medullary carcinoma of the colon with an emphasis on intestinal differentiation. Hum Pathol 2009; 40:398-404. 